\title{
Role of Customer Service Skills on Customer Satisfaction and Its Effects on Customer Loyalty in Pakistan Banking Industry
}

\author{
Muhammad Ali * $\quad$ Khalid M. Iraqi ${ }^{\dagger} \quad$ Amna Sohail Rawat ${ }^{\ddagger}$ \\ Shoaib Mohammad ${ }^{\S}$
}

\begin{abstract}
Companies offer different products and services to differentiate themselves from their competitor. In an organizations, employee's abilities and skills to deal with the customers play an important role in succeeding businesses. They offer superior services to their customers that leads to satisfaction. It has become an essential marketing strategy nowadays. Therefore, in this study we try to investigate the role of customer service skills on customer loyalty via customer satisfaction. Generally, bank customers aware of service facility, but the leading factors to select the best service provider bank are to get more comfort and to save time. Due to this fact, the study examined the effect of problem solving skills, reputation building, customer service culture, Nonverbal and verbal communication skills on which customers' intend to select best Pakistani banks. A sample data of 350 respondents is used to test the hypothesis. Exploratory factor analysis (EFA) and confirmatory factor analysis were used to test the measurement model and structural equation modeling is used to test the hypothesis. Findings from analysis suggest that reputation building skills (RBS), Problem solving skills (PSS), Customer service culture (CSC), nonverbal and verbal communication skills (NVCS) show positive and significant impact on customer satisfaction. It is recommended that, bank should educate their employee about how to deal with customer polite and soft skills to compete with other banks in market and develop marketing strategies through social media and other marketing channels to change consumer's attitude in favor of their particular bank.
\end{abstract}

Keywords: Customer service skills, customer satisfaction and customer loyalty.

\section{Introduction}

Customer servicing has become a field of greater interest for academics and practitioners over the past two decades. To get a separate marketplace, to survive in the competitive market and to get distinguished recognition, the organizations have to understand the importance of providing a good service encounter and interaction. Organizations have also need to work on the skills and competencies of their employees. Customer service has become an essential part of the marketing strategy of the firm. The reason being that the majority of the elements of marketing strategy have become standardized and

\footnotetext{
*Department of Management Sciences,IQRA University, Karachi, Pakistan. Email: alisaleem_01@yahoo.com

${ }^{\dagger}$ Department of Public Administration, University of Karachi, Karachi, Pakistan.

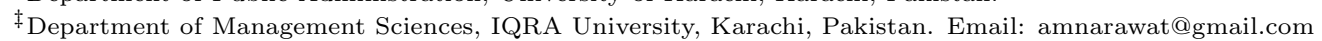

$\S$ Department of Management Sciences,IQRA University, Karachi, Pakistan.
} 
customers usually perceive them as they are, especially in the services sector, where the customer finds it difficult to distinguish them. Hence, if the organizations want a distinguished recognition, they can achieve it by providing superior customer services and this kind of offering require high-quality employees, who possess skills and competencies which are necessary for achieving customer satisfaction and customer loyalty. Various previous studies (Akroush, Shibly, \& Khawaldeh, 2005) postulated that customers who receive good treatment from the service provider, perceive the service provider positively, and are more loyal, less complaining, more cooperative and are ready to pay a higher price which can ultimately, lead to a greater profit.

Customer satisfaction is also an area of major interest for marketing and management research over the past few decades and the association between satisfaction and loyalty have become almost intuitive (Cronin Jr \& Taylor, 1992). The theoretical and conceptual foundations of customer satisfaction have been explored by many researchers. Findings explored that customer satisfaction is a major driver of the customer loyalty. Several past studies also support the notion that customer satisfaction is an imperative element for the long-run business success (Zeithaml, Berry, \& Parasuraman, 1996). Companies having a satisfied customers, earn greater economic returns (Aaker \& Jacobson, 1994).

Although a well-established link exist between customer service, customer satisfaction and customer loyalty (Marr, 1984; Smith \& Lewis, 1989), our knowledge of customer service literature indicates that little research effort have been dedicated to investigate the link between customer service skills and customer loyalty via customer satisfaction. The contribution of this research is the identification of customer services skills and competencies that work as requisites for achieving customer satisfaction that ultimately brings about customer loyalty. Although, past researches have invested effort in the field of customer satisfaction, still businesses are facing declining customer satisfaction rates. A plausible reason could be that even effective customer service often fails to address important issues of verbal and nonverbal communication, profitability of the firm, strategic aspects of customer services, and well trained customer services staff. Therefore, a service organization needs to take care of its customer service so as to increase its customer satisfaction and customer's loyalty for competing in today's highly competitive business environment. If customers will be satisfied and can see the value in the offered customer service, there repeat purchase intention is likely to increase (Goodman, 1999).

With the statements given above, the question arises that what are the determinants of customer servicing skills and what is their effect on the customer satisfaction. The study wants to examine that whether the presence of the individual employee's customer service skills brings about customer satisfaction and customer loyalty in services businesses. Customer service is important to study because it is closely related to customer satisfaction and finally to customer loyalty. It can also increase the profitability of the firm (Duncan \& Elliott, 2002, 2004). If the range of service product line and their branding is established by the services firm, it is imperative to form an extensive customer service program. The study, hence, develops an empirical and integrated model of customer services skills, customer loyalty and customer satisfaction. By bridging this gap, we aim to extend our understanding about the customer services skills that should be acquired by the employees of the services sector in order to satisfy their customers and keep them loyal. 
Pakistani market is unique and has become international in the past few years with increased modernization, regulation and privatization. Banking sector of Pakistan is on a high growth trajectory. It has shown the highest growth in the private sector as compared to the public in last ten years. Because of the high growth rate in the banking sector, an increase in the assets is also being anticipated. Deposits have also increased and have maintained a steady growth. The effects of easy monetary policy, sufficient availability of liquidity, CPEC related trade activities and increase in economic growth are the major determinants of impressive advances in the banking sector, (State Bank of Pakistan, 2016). From the viewpoint of international marketing, research on non-Western samples that focuses on the all aspects of marketing mix for developing countries is greatly required. Taking the current boom of services, especially banking sector of Pakistan in account, there is a strong need to assess the role of customer services skills in developing customer satisfaction and customer loyalty for Pakistani banking sector's consumers. Most of the studies that have dealt with customer services have shed light on this issue in the Western and developed countries' context. Little emphasis have been vested on developing countries environment. The findings of the present study will provide the banking sector in particular and services sector in general, the theoretical and empirical groundings of the required skills for customer servicing in order to provide superior level of customer services. The remaining part of the study is organized as follows, the next part of the study deals with the past studies on the same topic. Section III of the study explains the methodology applied to formulate the empirical findings. Section IV contains the empirical findings of the proposed framework whereas, section $\mathrm{V}$ concludes the study with suitable practical and managerial implications.

\section{Theoretical Background}

Business and operation is an official and legal activity that is adopted and done to earn profit. Business performance can be measured and divided into 3 categories, i.e., manufacturing, (conversion of input into output by a revolution process), trading (selling and buying of goods) and services (terms of benefits for fee or rewards). Services are defined and explained as a set of rewards and benefits delivered by a customer service provider to their consumer. The customer service firm provides benefits and rewards (due to skills, capability, experience and knowledge etc.) to customers for the sake of benefits and reward (fees, salaries, wages, fee etc.).

Financial deregulation and liberalization has amplified the tough competition among banks to attract likely customers. All bankers try to provide best possible services to respected customers to keep them satisfied. Customer satisfaction is a set of desire and feelings or result attached with customer's familiarity towards any provided product/service . Customer satisfaction is a collective outcome of evaluation, psychological and perception thinking of customers when they make use of any service provided by banks. There are a lot of studies that measured and evaluate the customer fulfillment towards customer services in the competitive banking sector (Anderson \& Gerbing, 1988). The most satisfied customer are the real \& basic asset for any big organization that ensures long-term output and 
profitability even in the time of great competition.

Oliver (1980) describes customer loyalty as a strongly held commitment of consumers to re-buy a product consistently in future as well in spite of several situational and marketing influences that might cause switching behavior. A number of past researches have emphasized the importance of customer loyalty for the future stability and growth of the firm (Calik \& Balta, 2006). Several authors have advocated that customer satisfaction acts as an antecedent to customer loyalty.

Figure 1 below describes the research framework and the hypothesized relationships among variables which are developed based on customer service skills, customer satisfaction and customer loyalty literatures.

Figure 1

Research Framework

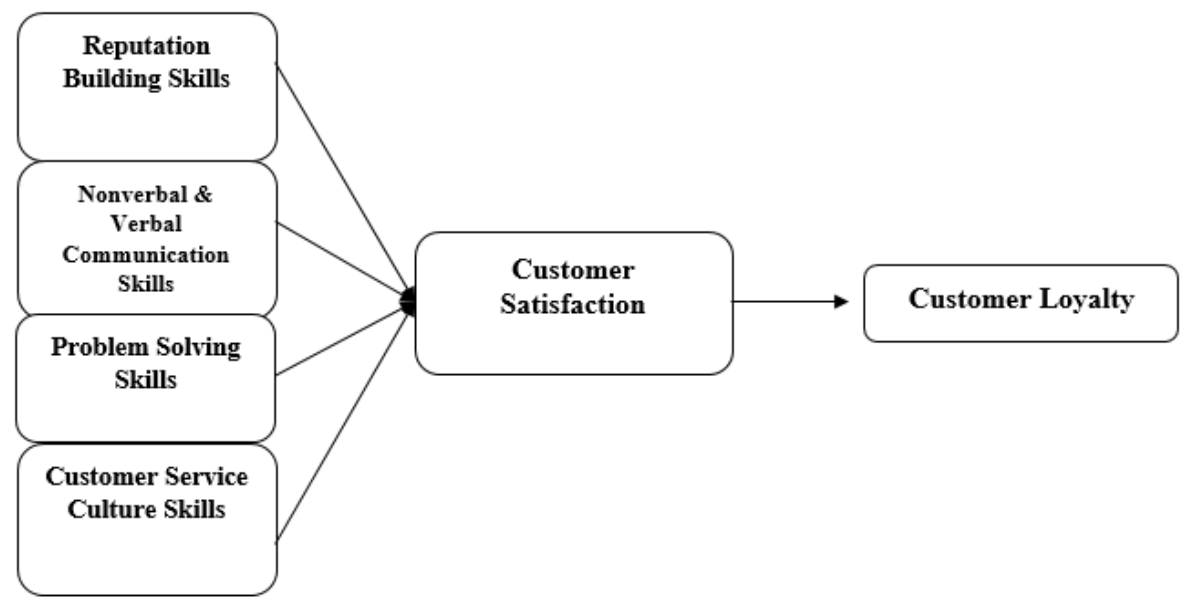

\section{Research Framework}

\section{Empirical Studies}

Literature shows that there is a strong appealing evidence that reveals that employees' skills and competencies are the requisites for creating a good repute of organizations for customers (Aaker \& Jacobson, 1994; Doyle, 1999). In the same vein, Hansemark and Albinsson (2004) emphasized that service quality is a very important factor for the managers to compete in this highly competitive environment. Therefore, organizations must ensure improvement in their customer servicing skills in order to meet customer's needs and wants. Similarly, Lonial and Raju (2015) examined the role of perceived service attributes in determine the overall customer satisfaction and loyalty for health-care sector. Their findings showed that organizations can prosper by identifying and focusing on serious attributes as part of their customer relationship management plan so as to attain customer satisfaction. Their study also suggested that organizations should make strategic use of service quality attributes in order to achieve customer loyalty. 
Osayawe Ehigie (2006) identified the manner in which perceived service quality and satisfaction can predict customer loyalty among bank customers in Nigeria. The findings of the study indicated that service quality and satisfaction are highly co-related with customer loyalty. According to the author, they are key variables that can create positive brand image. However, a contrasting evidence was found by Bennett and Rundle-Thiele (2004). The authors claimed that customer satisfaction is often considered as the proxy of customer loyalty and other outcomes. However, it is not the case. The authors proposed that while satisfaction and loyalty are considered to be highly co-related variables but a greater level of satisfaction does not always lead to greater loyalty. Therefore, in business settings, they both should be considered as two different constructs. A framework in which satisfaction, as a mediator is responsible for the relationship between service recovery characteristics and post recovery Behavior (For e.g., repurchase intention). The study found out that since service failures are an important task to deal for the managers, hence they should build a stronger brand equity so that post failure satisfaction and behavioral intentions can be maximized.

Following the same notion, Yang and Peterson (2004) examined the moderating effects of switching cost on customer loyalty through satisfaction and perceived value measures. The findings of the study indicated that the moderating effects of switching costs on the relationship between loyalty and satisfaction and perceived value and satisfaction are only significant when the levels of perceived value and satisfaction are above average. Ngoc Phan and Ghantous (2013) investigated how to accomplish brand association to drive customers' trust and loyalty in Vietnamese banking industry. The findings proposed that customers' personal attachment has positively related with trust while it has a negative relationship with loyalty. Tsoukatos and Rand (2006) examined the relationship between perceived service quality, satisfaction and loyalty in Greek insurance industry. The findings suggested that service quality is a determinant of satisfaction and satisfaction does also lead to loyalty. The authors claimed that the findings of the study can be used by the managers of the insurance industry who are willing to retain their customers and want to improve the loyalty level of their customers.

\section{Hypothesis Development}

From the above empirical reviews, we have developed following hypothesis;

$H_{1}$ : Reputation building skills have a positive impact on customer satisfaction.

$\mathrm{H}_{2}$ : Problem Solving Skills have a positive impact on customer satisfaction.

$H_{3}$ : Non-verbal \& verbal communication skills have a positive impact on customer satisfaction.

$H_{4}$ : Customer service culture has a positive impact on customer satisfaction.

$H_{5}$ : Customer satisfaction has a positive impact on customer loyalty. 


\section{Research Methodology}

\section{Population and Sample}

The study is carried out in Pakistan using the target population of bank customers who have at least one or two bank accounts. To draw a sample, we have used convenience sampling technique. Acoording to Ali, Raza, and Puah (2017); Ali, Raza, Puah, and Karim (2017); Ali, Raza, Qazi, and Puah (2018), a sample of 1000 is regarded as excellent, 500 as very good, 300 as good and 50 as poor. A sample data of 320 respondents were gathered from different public and private bank customers. Data has been collected by disseminating questionnaires among different male and female bank customers and university students who holds a bank account.

\section{Measures}

To measure the constructs, scales were drawn from the existing literature on customer satisfaction, customer service skills and customer loyalty. Customer service skills use as an independent variable carries five constructs and each of the constructs were drawn from the study of El (Akroush et al., 2005). The constructs of customer service skills are; reputation building skills, problem solving skills, verbal communication skills, nonverbal communication skills and customer service culture. Customer satisfaction uses as a mediating variable that further divided into three constructs; overall customer satisfaction, functional customer satisfaction and technical customer satisfaction. Each of the constructs carries five items. Moreover, customer loyalty is taken as a dependent variables and also carrying five items. The items of both customer satisfaction and customer loyalty are adopted from Hallowell (1996). All the constructs were measured using five-point Likert scale ranging from "Strongly Disagree" (1) to "Strongly Agree" (5).

\section{Statistical Analysis}

For data analysis, we have used several statistical techniques. For example, we use exploratory factor analysis, confirmatory factor analysis, reliability test and model fitness test to check the measurement of the model. Further, we apply structural equation modeling to estimate the structural model.

\section{Results and Discussion}

\section{Descriptive Statistics}

The descriptive results of the respondents are illustrated below in table 1. It indicates the highest proportion of male respondents approx. $70 \%$, whereas, the female respondents are only $29 \%$. Out of 350 respondents, the age of 143 respondents are below 25 . The sample contains the highest proportion of respondents who holds a bachelor's degree (44.6\%). This table also illustrates the job experience of the respondents. According to the table, 
$70 \%$ respondents are the private employees having the monthly salary of 20,000 to 30,000 . Further, the majority of the respondents approximately $73 \%$ are the current account holders in conventional banks and only $11 \%$ holds an account in Islamic banks.

Table 1

Demographic profile of Respondents

\begin{tabular}{|c|c|c|}
\hline & Frequency & $\%$ \\
\hline \multicolumn{3}{|l|}{ Gender } \\
\hline Male & 226 & 70.63 \\
\hline Female & 94 & 29.38 \\
\hline \multicolumn{3}{|l|}{ Age } \\
\hline Below 25 & 143 & 44.68 \\
\hline $26-30$ & 123 & 38.44 \\
\hline $30-40$ & 38 & 11.88 \\
\hline 40 plus & 16 & 5 \\
\hline \multicolumn{3}{|l|}{ Marital Status } \\
\hline Married & 123 & 38.44 \\
\hline Unmarried & 197 & 61.56 \\
\hline \multicolumn{3}{|l|}{ Education Level } \\
\hline M.Phil. & 3 & 0.94 \\
\hline Masters & 102 & 31.88 \\
\hline Bachelors & 204 & 63.75 \\
\hline Others & 11 & 3.44 \\
\hline \multicolumn{3}{|l|}{ Occupation } \\
\hline Govt. Employee & 39 & 12.19 \\
\hline Private Employee & 227 & 70.94 \\
\hline Self Employed & 32 & 10 \\
\hline Others & 22 & 6.88 \\
\hline \multicolumn{3}{|l|}{ Monthly Salary } \\
\hline Below 19,999 & 68 & 21.25 \\
\hline $20,000-30,000$ & 173 & 54.06 \\
\hline $31,000-40,000$ & 36 & 11.25 \\
\hline 41,000 Plus & 43 & 13.44 \\
\hline \multicolumn{3}{|c|}{ Holding Bank Account } \\
\hline Within 1 Year & 54 & 16.88 \\
\hline 1-2 Years & 158 & 49.38 \\
\hline 3-4 Years & 75 & 23.44 \\
\hline 5 or More & 33 & 10.31 \\
\hline \multicolumn{3}{|l|}{ Type of Account } \\
\hline Current & 234 & 73.13 \\
\hline PLS Saving & 76 & 23.75 \\
\hline Investment & 3 & 0.94 \\
\hline Others & 7 & 2.19 \\
\hline \multicolumn{3}{|l|}{ Type of Bank } \\
\hline Conventional Bank & 235 & 73.44 \\
\hline Islamic Bank & 36 & 11.25 \\
\hline Both & 49 & 15.31 \\
\hline
\end{tabular}

\section{Exploratory Factor Analysis}

To establish the structure of the observed variables, we have used exploratory factor analysis (EFA) and reliability test. The statistics of KMO and Bartlett test ensures the adequacy of the sample. The minimum criteria for an adequate sample is 0.7 . However, the value above 0.9 considers an excellent, above 0.8 as very good, above 0.7 is acceptable and less than 0.5 is unacceptable. In this study, table 2 illustrates the results that shows the sample 
is adequate because the value of KMO sampling adequacy is $92 \%$ and the Bartlett test is also significant at the $5 \%$ significance level.

Table 2

Result of KMO and Bartlett's Test

\begin{tabular}{lcc}
\hline Kaiser-Meyer-Olkin Measure of Sampling Adequacy. & & 0.927 \\
Bartlett's Test of Sphericity & Approx. Chi-Square & 7023.012 \\
& degree freedom & 435 \\
& Probability & 0.000 \\
\hline Source: Authors' estimations &
\end{tabular}

After examining the sampling adequacy, the structure of the observed variables are established by using rotated component matrix. It is used to examine the relationship between the items of latent variables and also ensures the construct validity. Table 2 reports the factor loadings of all the variables. The values of factor loading of each variable shows the correlation between the measured variables.

In this case, from the total 39 items, 30 were loaded and divided into six factors and rest of the 9 items were cross loaded or have weak correlations. These six factors comprises of non-verbal and verbal communication skills, reputation building skills, customer service skills, problem solving skills, customer satisfaction and customer loyalty. All the items have factor loading greater than 0.5 , which is greater than the proposed criteria. According to them, factor loadings of each item should be greater than 0.4 in the sample of 320 or above. Moreover, Eigen values illustrated in table 2 explain the variance of the constructs. Each factor considers sufficient if the Eigen value is greater than 1.0. Similarly, in our case, all the factors are sufficient because the Eigen values of each factor is greater than 1.0. In addition, the reliability test has also been applied on the established six factors, table 2 displays the results of reliability test that shows the statistics of overall as well as the individual reliability of the observed variables. The Cronbach for the nine items of nonverbal and verbal communication skills is 0.932 , which is the highest among all. Whereas, the overall reliability of the variables is 0.963 , which is also acceptable because it exceeds the proposed criteria of 0.5 or above.

\section{Confirmatory Factor Analysis}

In the next step, we have applied confirmatory factor analysis to confirm the dimensionality of the constructs derived from the exploratory factor analysis (EFA). For structural equation modeling, CFA is considered the most appropriate method which validates the hypothesized measurement model. To check the fitness of the proposed model, we performed confirmatory factor analysis. A total number of 30 items were loaded that confirms the fitness of all the measured variables because the factor loadings are ranging between 0.52 to 0.86 , which exceeds the threshold level i.e. 0.6. Furthermore, table 3 shows the value of RMSEA also confirms the construct and convergent validity of the model because the value exceeds the benchmark (0.056). As Atilgan (2005) notified that the model is consider fit if the RMSEA value lies within or equal to 0.08 . In this case, we have tested the fitness of our measurement model by using the goodness-fit measures. Table 3 displayed the results of model fitness and all the indicators fulfills the minimum cutoff criteria. Thus, 


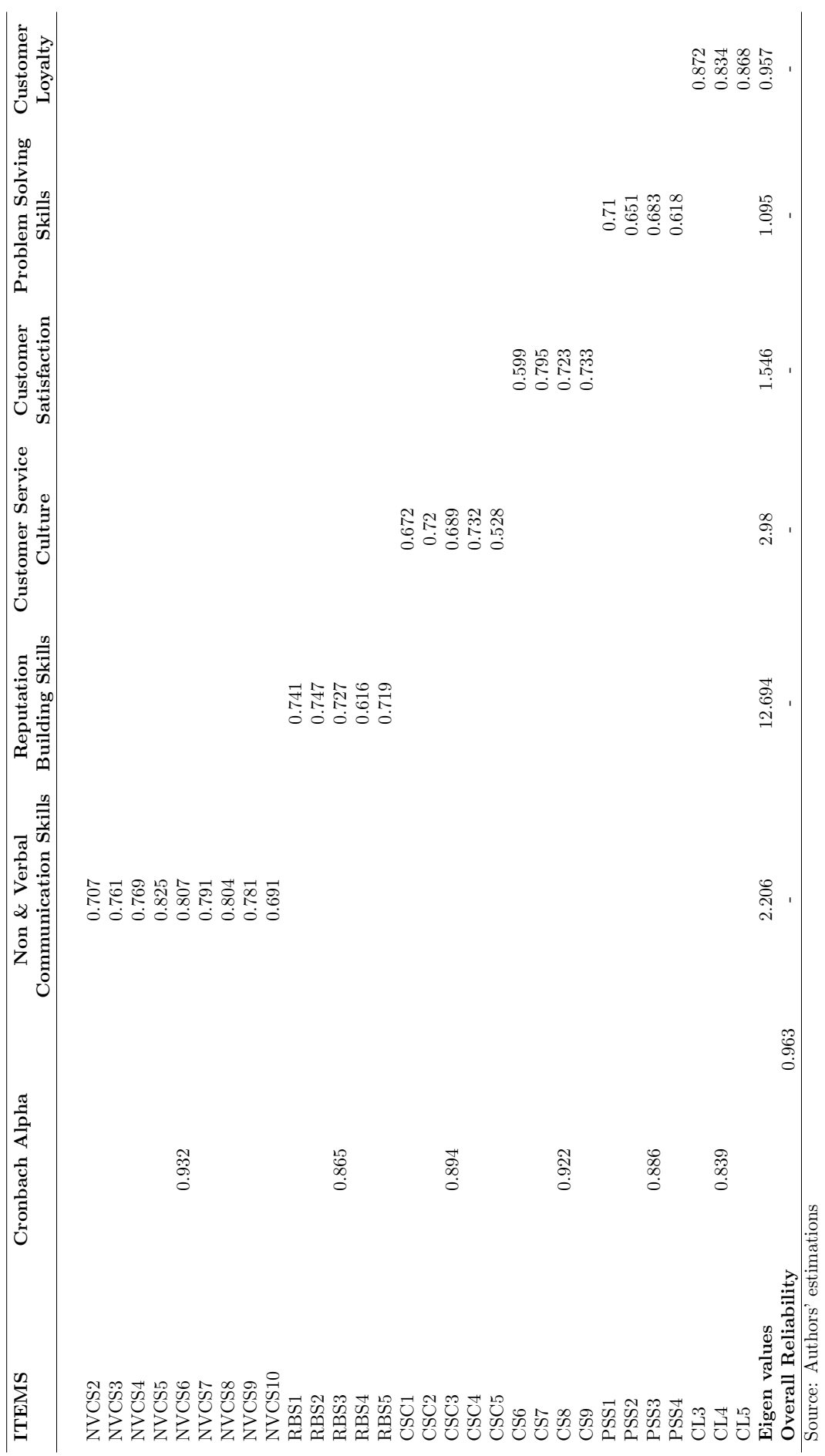


we conclude that our measurement model is appropriate to predict the role of customer service skills on customer satisfaction and customer loyalty.

\section{Structural Equation Modeling: Model and Hypothesis Testing}

The proposed structural model is estimated by structural equation modeling. After confirming the factors using CFA, the next step is to test and analyses the hypothesized relationship between considered variables. Anderson and Gerbing (1988) proposed two-step for testing mediating relationship, one is to develop a measurement model by conducting CFA and second is to test hypotheses using structural model. In this study, we have adopted a same approach proposed by Anderson and Gerbing (1988), and test a mediating effect of customer satisfaction on the relationship between customer service skills and customer loyalty. We develop a mediation model in which the first path is created from customer service skills to customer satisfaction and then second path from customer satisfaction to customer loyalty. The results of the path analysis are displayed in table 4 . It shows that non-verbal and verbal communication skills is positively and significantly related to customer satisfaction ( $\mathrm{p}=0.007)$, problem solving skills is also positively and significantly influence customer satisfaction $(\mathrm{p}=0.047)$, customer service culture is highly significant $(\mathrm{p}=0.000)$ and positive to customer satisfaction. Contrary to others, reputation building skills is positive but insignificant $(\mathrm{p}=0.298)$ with customer satisfaction. In the second path, customer satisfaction is also found significant $(\mathrm{p}=0.000)$ and positive with customer loyalty.

Table 3

Model of Fitness

\begin{tabular}{lcccccc}
\hline Goodness of fit measures & GFI & AGFI & NFI & CFI & TLI & RMSEA (PCLOSE) \\
\hline Threshold values & $\geq 0.85$ & $\geq 0.80$ & Close to 1 & $\geq 0.90$ & Close to 1 & $\leq 0.08(>0.05)$ \\
Measurement model & 0.881 & 0.849 & 0.902 & 0.948 & 0.938 & $0.056(0.063)$ \\
Structural model & 0.882 & 0.851 & 0.902 & 0.949 & 0.940 & $0.055(0.085)$ \\
\hline
\end{tabular}

Source: Authors' estimations

Table 4

Structural equation modeling

\begin{tabular}{cccccc}
\hline Hypothesis & Variable & Regression Path & Estimate & P-Value & Remarks \\
\hline H1 & Non \& verbal communication skills & NVCS $\rightarrow$ CS & 0.185 & 0.007 & Supported \\
H2 & Reputation Building skills & RBS $\rightarrow$ CS & 0.123 & 0.298 & Not Supported \\
H3 & Problem Solving Skills & PSS $\rightarrow$ CS & 0.237 & 0.047 & Supported \\
H4 & Customer Service Culture & CSC $\rightarrow$ CS & 0.43 & 0.000 & Supported \\
H5 & Customer Loyalty & CS $\rightarrow$ CL & 0.445 & 0.000 & Supported \\
\hline \multicolumn{2}{l}{ Source: Authors' estimations }
\end{tabular}

The above empirical findings confirmed the prediction that the customer service skills have a significant role in customer satisfaction that further leads to customer loyalty. However, the individual relationship between variables are all not found same. The role of non-verbal and verbal communication skills on customer satisfaction found important and hence supported H1. This finding is similar to Freemantle (1994). Moreover, reputation building skills have a positive but insignificant impact on customer satisfaction, though the 
H2 supported but this dimension is unimportant in our context. Smith and Lewis (1989) support our findings. In addition, customer service culture found an important dimension that influence customer satisfaction. Customer oriented culture in service industries plays a key role in customer satisfaction. Hence, the $\mathrm{H} 4$ is supported because both have positive and significant relationships. Whereas, problem solving skills has a positive but insignificant impact on customer satisfaction. Finally, our results support H5, which reveals that the positive and significant relationship of customer service skills and customer loyalty mediating by customer satisfaction. Similar results also found by Parasuraman, Zeithaml, and Berry (1985). All the results conclude that the selected customer service skills dimensions have an important role in enhancing customer satisfaction which leads to customer loyalty. A body of literature supports the notion that customer service skills are important but not enough to maintain loyal customers, unless to fulfill customer needs and satisfaction (Aaker \& Jacobson, 1994).

\section{Conclusion}

In this competitive world, companies have started offering superior services to their customers in order to differentiate themselves from their competitors. Customer service skills considers an imperative marketing strategy which leads to customer satisfaction and customer loyalty. Therefore, in this study, we have tried to investigate the role of customer service skills on customer loyalty via customer satisfaction. This research has conducted on a banking sector of Pakistan because normally it is observed that banks encounter more customer interaction than any other organizations. This study has contributed to the existing literature in several ways, first, this research is a first attempt to study the role of customer service skills in a developing countries business environment i.e. Pakistan. Second, the findings of this study is generalized on a banking sector which is considered highly interactive organizations as compared to others.

For analysis, we have gathered 350 sample of data from the people who holds an account in a conventional or Islamic banks, located in Karachi. Four dimension of customer service skills such as reputation building skills, problem solving skills, non-verbal and verbal communication skills, customer service culture are used as a predictor, whereas, customer satisfaction is a mediator and customer loyalty is taken as a response variable. Prior estimating the structural model, we have evaluated the validity and reliability of the measurement model by using several statistical techniques. After confirming the validation of the measurement model, we estimate the proposed model using structural equation modeling (SEM). The results suggests that non-verbal and verbal communication skills play a key role in the satisfaction of customers. Similarly, problem solving skills in employees also boost the satisfaction level of bank customers. Our statistics also supports the customer service culture that highly influencing the customer satisfaction which leads to customer loyalty. However, reputation building skills is also found positive but unimportant in our context. The findings also suggests that if customers are satisfied with the services, they will become loyal. The statistics show that customer satisfaction has a highly significant and positive relationship with the customer loyalty. 


\section{Managerial Implications}

This research findings have several important managerial implications and the results are particularly useful for the decision makers of banking sectors. As results suggest, nonverbal and verbal communication skills, reputation building skills, problem solving skills and customer service culture are the important factors of customer service skills that enhance customer satisfaction, therefore, banking sectors should focus on the training of their employees on enhancing all the dimensions. Banks should train their employees about the body language at the time of dealing with customers because non-verbal skills also create an impression about the company. In addition, problem solving skills is one of the pivotal factors that increases the satisfaction level of customers. Banks should create a learning-oriented environment that facilitates employees to become multi-tasking, improves verbal communication due to frequent interactions and develop problem solving skills. This study provides a model for the managers to retain loyal customers. It is found from our findings that the availability of customer service skills is not merely important but the delivery of these services create an impact on the customer satisfaction level which also keep them loyal. Thus, it is essential for the banks to develop customer service skills in their employees that make customers satisfies and loyal.

\section{Recommendations for Future Researches}

Likewise all the empirical researches, our study also has some limitations. Though our model is backed by a theory but its generalizable is restricted to a single industry i.e. banking sector of Pakistan. For future research, our model can also be used on another service sector in other region i.e. advanced or emerging countries. Moreover, a regional comparative study on a same model is highly encouraged. In our study, we have used only four dimension of customer service skills, in future, researchers can also add some other factors such as customer expertise, customer service abilities, relationship marketing and customer subscription duration in the model. Finally, researchers can separately study on the customer services skills of Islamic banking and conventional banking. 


\section{References}

Aaker, D. A., \& Jacobson, R. (1994). The financial information content of perceived quality. Journal of Marketing Research, 31(2), 191-201.

Akroush, M., Shibly, M., \& Khawaldeh, F. (2005). The effect of services marketing mix elements on customers satisfaction in the comprehensive motor insurance: An empirical investigation of customers perspectives in Jordan. Journal of Financial and Commercial Studies/Managerial Sciences-Cairo University, 32, 439-72.

Ali, M., Raza, S. A., \& Puah, C.-H. (2017). Factors affecting to select Islamic credit cards in Pakistan: The TRA model. Journal of Islamic Marketing, 8(3), 330-344.

Ali, M., Raza, S. A., Puah, C.-H., \& Karim, M. Z. A. (2017). Islamic home financing in Pakistan: A SEM-based approach using modified TPB model. Housing Studies, 32(8), 1156-1177.

Ali, M., Raza, S. A., Qazi, W., \& Puah, C.-H. (2018). Assessing e-learning system in higher education institutes: Evidence from structural equation modelling. Interactive Technology and Smart Education, 15(1), 59-78.

Anderson, J. C., \& Gerbing, D. W. (1988). Structural equation modeling in practice: A review and recommended two-step approach. Psychological Bulletin, 103(3), 411423.

Bennett, R., \& Rundle-Thiele, S. (2004). Customer satisfaction should not be the only goal. Journal of Services Marketing, 18(7), 514-523.

Calik, N., \& Balta, N. F. (2006). Consumer satisfaction and loyalty derived from the perceived quality of individual banking services: A field study in Eskisehir from Turkey. Journal of Financial Services Marketing, 10(4), 135-149.

Cronin Jr, J. J., \& Taylor, S. A. (1992). Measuring service quality: A reexamination and extension. Journal of Marketing, 56(3), 55-68.

Doyle, P. (1999). Building value-based brand strategies. In Academy of Marketing Annual Conference.

Duncan, E., \& Elliott, G. (2002). Customer service quality and financial performance among Australian retail financial institutions. Journal of Financial Services Marketing, 7(1), 25-41.

Duncan, E., \& Elliott, G. (2004). Efficiency, customer service and financial performance among Australian financial institutions. International Journal of Bank Marketing, 22(5), 319-342.

Freemantle, D. (1994). Customer service-getting the basics right. Managing Service Quality: An International Journal, 4(5), 46-50.

Goodman, J. (1999). Quantifying the impact of create customer service on profitability. Best Practices in Customer Service, 17-29.

Hallowell, R. (1996). The relationships of customer satisfaction, customer loyalty, and profitability: an empirical study. International Journal of Service Industry Management, $7(4), 27-42$.

Hansemark, O. C., \& Albinsson, M. (2004). Customer satisfaction and retention: The experiences of individual employees. Managing Service Quality: An International Journal, 14 (1), 40-57. 
Lonial, S., \& Raju, P. (2015). Impact of service attributes on customer satisfaction and loyalty in a healthcare context. Leadership in Health Services, 28(2), 149-166.

Marr, N. E. (1984). The impact of customer services in international markets. International Journal of Physical Distribution \& Materials Management, 14(1), 33-40.

Ngoc Phan, K., \& Ghantous, N. (2013). Managing brand associations to drive customers' trust and loyalty in Vietnamese banking. International Journal of Bank Marketing, $31(6), 456-480$.

Oliver, R. L. (1980). A cognitive model of the antecedents and consequences of satisfaction decisions. Journal of Marketing Research, 17(4), 460-469.

Osayawe Ehigie, B. (2006). Correlates of customer loyalty to their bank: A case study in Nigeria. International Journal of Bank Marketing, 24(7), 494-508.

Parasuraman, A., Zeithaml, V. A., \& Berry, L. L. (1985). A conceptual model of service quality and its implications for future research. Journal of Marketing, 49(4), 41-50.

Smith, A. M., \& Lewis, B. R. (1989). Customer care in financial service organisations. International Journal of Bank Marketing, 7(5), 13-22.

Tsoukatos, E., \& Rand, G. K. (2006). Path analysis of perceived service quality, satisfaction and loyalty in Greek insurance. Managing Service Quality: An International Journal, 16(5), 501-519.

Yang, Z., \& Peterson, R. T. (2004). Customer perceived value, satisfaction, and loyalty: The role of switching costs. Psychology \& Marketing, 21(10), 799-822.

Zeithaml, V. A., Berry, L. L., \& Parasuraman, A. (1996). The behavioral consequences of service quality. Journal of Marketing, 60(2), 31-46. 